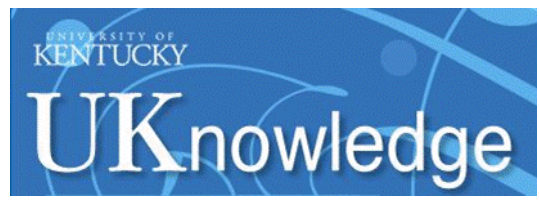

University of Kentucky

UKnowledge

\title{
Net Zero Energy Houses with Dispatchable Solar PV Power Supported by Electric Water Heater and Battery Energy Storage
}

\author{
Huangjie Gong \\ University of Kentucky, huangjie.gong@uky.edu \\ Vandana Rallabandi \\ University of Kentucky, vandana.rallabandi@uky.edu \\ Dan M. Ionel \\ University of Kentucky, dan.ionel@uky.edu \\ Donald G. Colliver \\ University of Kentucky, dcolliver@uky.edu \\ Shaun Duerr \\ Marquette University
}

See next page for additional authors

Follow this and additional works at: https://uknowledge.uky.edu/peik_facpub

Part of the Power and Energy Commons

Right click to open a feedback form in a new tab to let us know how this document benefits you.

\section{Repository Citation}

Gong, Huangjie; Rallabandi, Vandana; Ionel, Dan M.; Colliver, Donald G.; Duerr, Shaun; and Ababei, Cristinel, "Net Zero Energy Houses with Dispatchable Solar PV Power Supported by Electric Water Heater and Battery Energy Storage" (2018). Power and Energy Institute of Kentucky Faculty Publications. 33.

https://uknowledge.uky.edu/peik_facpub/33

This Conference Proceeding is brought to you for free and open access by the Power and Energy Institute of Kentucky at UKnowledge. It has been accepted for inclusion in Power and Energy Institute of Kentucky Faculty Publications by an authorized administrator of UKnowledge. For more information, please contact UKnowledge@lsv.uky.edu. 


\title{
Net Zero Energy Houses with Dispatchable Solar PV Power Supported by Electric Water Heater and Battery Energy Storage
}

\author{
Digital Object Identifier (DOI) \\ https://doi.org/10.1109/ECCE.2018.8557720
}

\section{Notes/Citation Information}

Published in 2018 IEEE Energy Conversion Congress and Exposition (ECCE).

(C) 2018 IEEE Copyright Notice. "Personal use of this material is permitted. Permission from IEEE must be obtained for all other uses, in any current or future media, including reprinting/republishing this material for advertising or promotional purposes, creating new collective works, for resale or redistribution to servers or lists, or reuse of any copyrighted component of this work in other works."

The document available for download is the authors' manuscript version that is accepted for publication. The final published version is copyrighted by IEEE and available as: H. Gong, V. Rallabandi, D. M. Ionel, D, Colliver, S.Duerr, and C. Ababei, "Net Zero Energy Houses with Dispatchable Solar PV Power Supported by Electric Water Heater and Battery Energy Storage," Rec. 2018 IEEE Energy Conversion Congress and Exposition (ECCE), Portland, OR, Sept 2018, pp. 2498-2503. doi: 10.1109/ECCE.2018.8557720.

Authors

Huangjie Gong, Vandana Rallabandi, Dan M. Ionel, Donald G. Colliver, Shaun Duerr, and Cristinel Ababei 


\section{Net Zero Energy Houses with Dispatchable Solar PV Power Supported by Electric Water Heater and Battery Energy Storage}

\author{
Huangjie Gong \\ SPARK Laboratory \\ ECE Dept. \\ University of Kentucky \\ Lexington, KY, USA \\ huangjie.gong@uky.edu
}

\author{
Vandana Rallabandi \\ SPARK Laboratory \\ ECE Dept. \\ University of Kentucky \\ Lexington, KY, USA \\ vandana.rallabandi@uky.edu
}

\author{
Dan M. Ionel \\ SPARK Laboratory \\ ECE Dept. \\ University of Kentucky \\ Lexington, KY, USA \\ dan.ionel@uky.edu
}

\author{
Donald Colliver \\ Bio-Systems \& \\ Agricultural Engr. Dept. \\ University of Kentucky \\ Lexington, KY, USA \\ dcolliver@uky.edu
}

\author{
Shaun Duerr \\ Electrical and Computer Engr. \\ Marquette University, \\ Milwaukeee, WI, USA \\ shaun.duerr@marquette.edu
}

\author{
Cristinel Ababei \\ Electrical and Computer Engr. \\ Marquette University, \\ Milwaukeee, WI, USA \\ cristinel.ababei@marquette.edu
}

\begin{abstract}
Over a year, net zero energy (NZE) houses produce and feed net metered electrical energy to the grid as much as they consume. Technical challenges, notably the 'duck curve' arise due to the fact that peak solar generation and load demand are seldom coincident. Common approaches to mitigate this limitation include the curtailment of solar power, and the use of storage. Surplus solar energy may be stored in a battery, which can subsequently be discharged to supply the home electricity needs when demand is in excess. In addition to batteries, less expensive electric water heaters, which are ubiquitous, can be modified as energy storage systems, functioning as 'uni-directional batteries' by virtue of their high thermal mass. This paper proposes the use of a hybrid energy storage system including both batteries and variable power electric water heaters in NZE residences. It is demonstrated that the virtual power plant control, with solar PV generation coordinated with hybrid energy storage system, would reduce the required battery size and ratings while still harvesting the maximum solar energy potential. Furthermore, a control strategy which enables the NZE homes to produce dispatchable power or behave like controllable loads is proposed.
\end{abstract}

Index Terms-Net Zero Energy (NZE) Residences, Home Energy Management (HEM), Electrical Water Heater (EWH), Battery Energy Storage System (BESS), Virtual Power Plant (VPP).

\section{INTRODUCTION}

The 'Net Zero Energy (NZE) Houses' concept is a timely topic of increasing interest due to the emphasis on renewable energy and concern over greenhouse gas emissions. For example, as per the California Public Utilities Commission, all new residential constructions will be NZE by the year 2020 [1]. A growing number of countries and US states have started to build NZE type residences at different scales, varying from single homes to big neighborhoods and their objectives range from reduced consumption to a net positive energy input to the grid. Modern NZE home designs incorporate solar photovoltaic (PV) systems as the main source of energy [2], [3].

Solar PV systems have limitations because of their unpredictable and stochastic nature, particularly when congregated in the same neighborhood [4]. This limitation results into issues caused by the mismatch between the peak solar PV generation and the residential load demand. This mismatch leads to an influx of power into the grid during periods of excess PV generation and small load, and to large withdrawals at times of dwindling solar power and increasing load demand. This variable load behavior is referred to as the 'duck curve'. In addition, the excess power generation can potentially lead to the operation of distribution lines and transformers beyond the rated capacity. Also, the intermittent nature of renewable energy sources can cause fluctuations in the system frequency. To mitigate these issues, a highly flexible power system is required to service such variable load and to keep the distribution systems within the rated capacity.

Other methods to address the above issues include curtailment of solar energy and the use of energy storage systems such as batteries that can produce dispatchable power. Solar energy can be curtailed by operating the solar panels in the constant power mode rather than at the maximum power point. This type of operation necessitates an increase in solar PV ratings for homes to achieve the NZE targets, and is therefore not desirable. On the other hand, producing dispatchable power while harvesting the maximum potential of PV generation during different conditions of irradiance would necessitate the use of high energy batteries, which might not be economical [5]. Electric water heaters $(\mathrm{EWH})$, with high thermal mass, constitute other sources of energy storage and also 


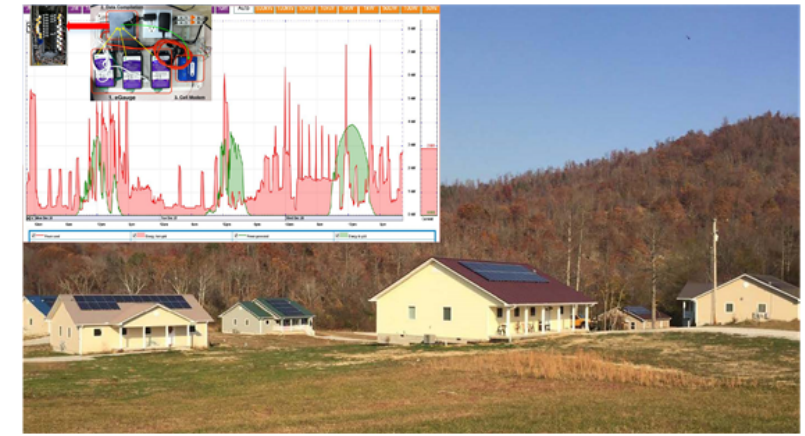

Figure 1. Currently existing NZE homes in southern Kentucky. These homes are modeled within EnergyPlus which is used to calculate the instantaneous power demand, validated with measured load data collected by the online system of these homes.

have advantages of universal availability and straightforward, flexible methods of control [6], [7]. Electric water heaters also constitute the largest electric load in the house with peak values of $5 \mathrm{~kW}-6 \mathrm{~kW}$, and virtually the only home energy storage device. Owing to the large thermal inertia, the EWH load naturally lends itself to demand side management. For example, it can be shifted from times of low to high PV availability, which potentially leads to a reduction in the peak power delivery to the grid during periods of high generation and low load.

This paper proposes the combined use of battery energy storage (BES) and variable power EWH for energy storage in NZE houses. The solar PV system and this hybrid PV energy storage system (HyPVESS) are interconnected via a common multiport DC-AC converter with the home power supply. The energy storage system controls are coordinated with the solar PV generation such that each NZE home behaves like a virtual power plant (VPP) with controllable and flexible generation or load. The control scheme ensures that the solar PV system is always operated at its maximum power point by feeding a part of the surplus energy to the grid, and storing the rest of it in the hybrid energy storage system.

This paper outlines the main concepts and procedures associated with sizing and scheduling operations of the HyPVESS. More specifically, a methodology based on multi-objective differential evolution (DE) optimization which minimizes both battery size and variation in grid power flow is proposed and illustrated for NZE homes in the mild Californian climate. The paper also includes a study with a community of 60-NZE homes equipped with the proposed HyPVESS connected to an IEEE 13-node test feeder system to verify the benefits of the system at the district level. It is demonstrated that the use of the HyPVESS mitigates the challenges associated with solar power variability, such as the 'duck curve'. Simulations are conducted with a simulation framework constructed with EnergyPlus for building energy consumption modeling and OpenDSS for system simulations.

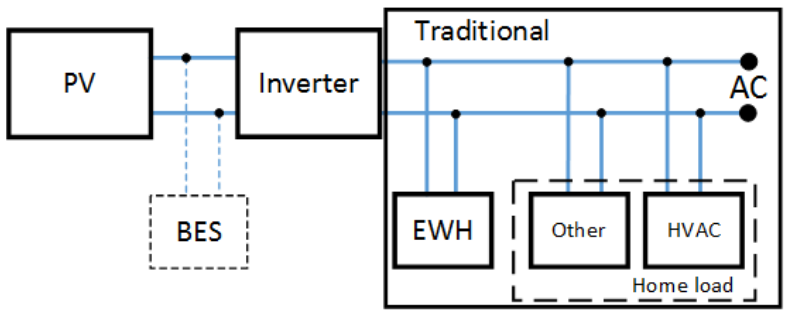

(a)

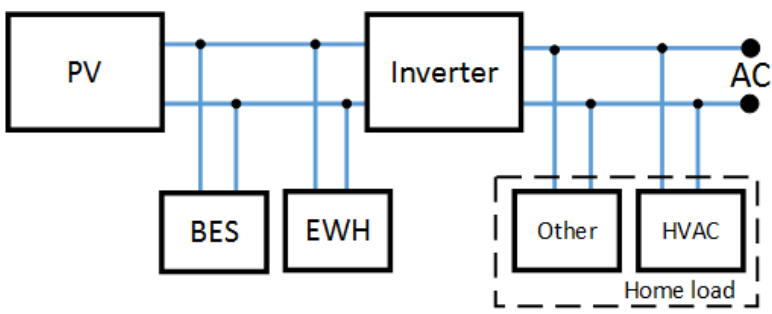

(b)

Figure 2. House types used for case studies (a) Home including rooftop PV panels without energy storage systems. (b) Home including a hybrid energy storage system with a BES and variable power DC EWH.

\section{Hybrid ENERgy Storage SYSTEM}

Net zero energy homes (Fig. 1) include rooftop solar PV panels which enable them to locally meet load demands, thereby minimizing power absorbed from the utility grid. During periods of high solar power availability, the homes behave like generators, feeding power to the grid. The interconnection of the solar PV and hybrid energy storage system of the NZE homes with the utility is illustrated (Fig. 2).

Appropriate control of the HyPVESS ensures that each NZE home behaves like a flexible and controllable generator or load. The operation schedules of the HyPVESS are such that each home provides or absorbs from the utility grid a constant power for a specified duration of time. During periods of excess solar radiation, a specified part of the power is supplied to the grid, and the BES and EWH are controlled to store the rest of the power. At times when only a limited amount of solar energy is available, a controlled amount of power flow between the home and the grid is established, and the energy stored in the BES is used to supply the residential load deficit. Thus, the issues stemming from the variability of solar power including high rate of change of load, line and transformer overloading are mitigated. Although, in principle, a battery can be sized to achieve these objectives, however, its capacity and power rating would become prohibitively high.

An example power electronic interface suitable for use in NZE houses to interconnect the solar panels with the hybrid energy storage system and the utility grid is shown (Fig. 3). A multi-port converter interconnects the solar PV panels, battery and variable power EWH to the DC bus, which feeds a single phase inverter connected to the utility and home loads. The converter is configured such that power flow to the PV and EWH systems is unidirectional. On the other hand, the power flow to the battery is bi-directional. The switch $S_{p v}$ is 


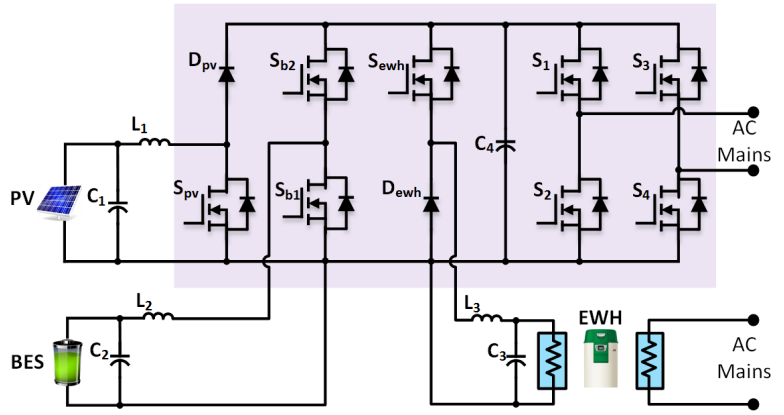

Figure 3. Example power electronic interface for an NZE house. The battery storage, electric water heater and PV array are interconnected with the DC bus via a multi-port converter.

modulated such that the PV system operates at its maximum power point. The inverter switches $S_{1}$ to $S_{4}$ are controlled to supply power to the grid and home loads at the specified voltage and frequency. The battery converter is controlled to regulate the dc bus voltage. Operation of $S_{b 1}$ and $S_{b 2}$ causes the battery to discharge and charge, respectively. The EWH absorbs the desired power from the DC bus by the modulation of $S_{\text {ewh }}$. The converter allows the DC bus voltage to be higher than that of the solar PV systems, battery and EWH.

In the traditional case, the EWH is generally equipped with conventional controls, which leads to a peak load in the evenings when solar power is unavailable (Figs. 4 (a) and (b)). A battery may be charged during midday to absorb the solar energy surplus, and this can be supplied to the EWH in the evenings, to avoid the absorption of peak power from the utility grid. This type of operation necessitates high battery power and energy ratings.

On the other hand, the solar PV coordinated controls of the EWH lead to the shifting of this load from the evening to a time in the middle of the day when solar power is in abundance (Figs. 4 (c) and (d)). This reduces the required energy capacity of the battery, which would otherwise have had to operate in the charging mode to absorb all the surplus solar power. Additionally, the use of a variable power EWH as opposed to a fixed power type reduces peak power demands, which leads to a further reduction in the required energy and power ratings of the battery.

\section{ENERGy StORAGE SizING AND SCHEDULING}

In the absence of energy storage, peak load demands are serviced by the absorption of power from the utility grid (Figs. 5 (a) and (b)). On the other hand, in NZE residences equipped with the HyPVESS, the operating schedules can ensure that the home provides dispatchable power to the grid, or behaves like a controllable load (Figs. 5 (c) and (d)). The variation of power flow to the grid is determined by the solar PV generation, as well as by the rating and operating schedule of the energy storage system, and more particularly that of the battery. A larger BES rating would lead to reductions in instantaneous variations of power delivered to the grid, while a smaller value would result in greater fluctuations in utility

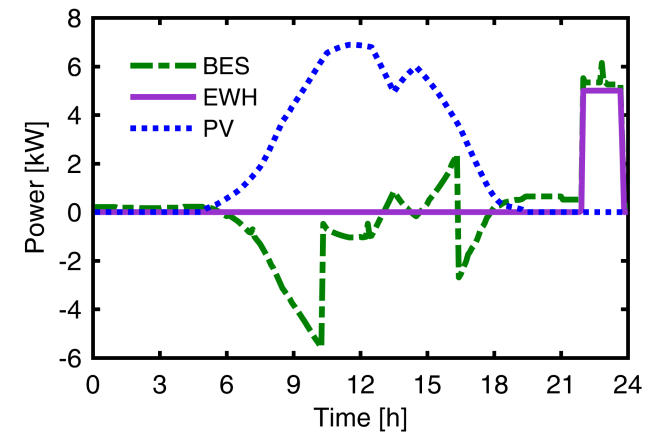

(a)

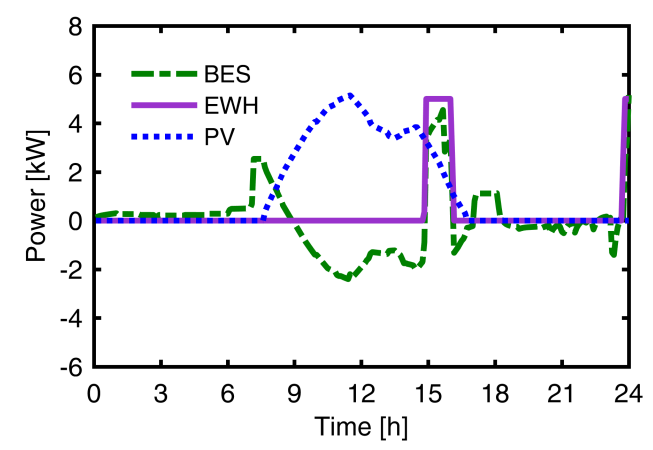

(b)

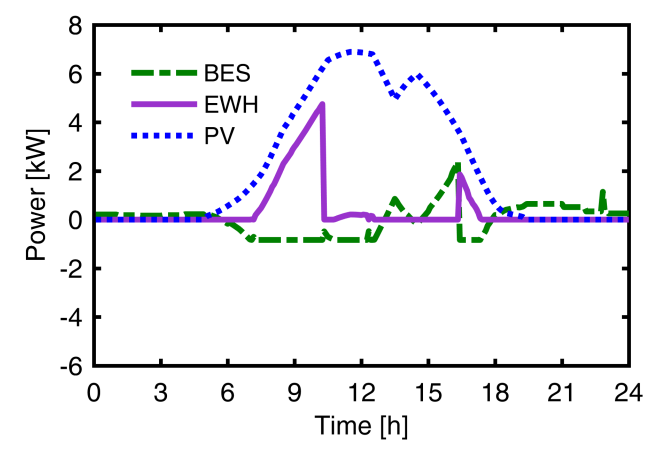

(c)

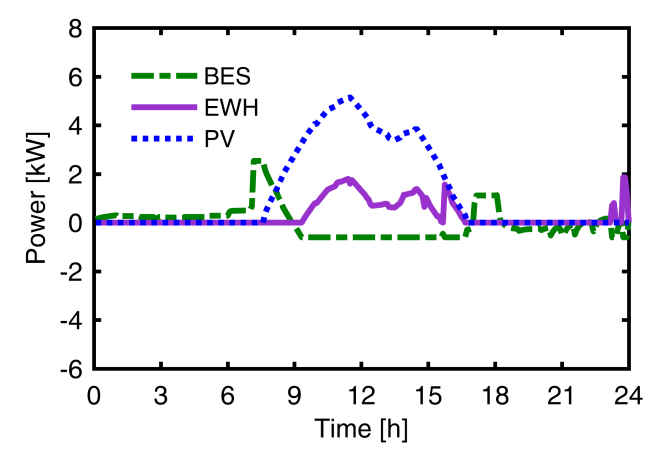

(d)

Figure 4. Battery and EWH schedules for a conventional scheme with a fixed power water heater equipped with traditional controls, for a representative (a) summer's day and (b) winter's day in California. Variable power water heater incorporating controls co-ordinated with solar power availability for the same representative (c) summer's day and (d) a winter's day. The variable power water heater and solar PV co-ordinated controls reduce the required battery power and energy ratings on both types of days. 


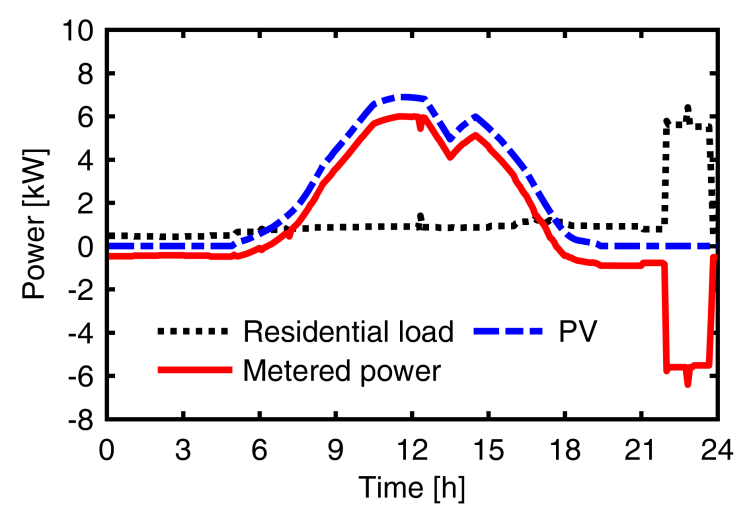

(a)

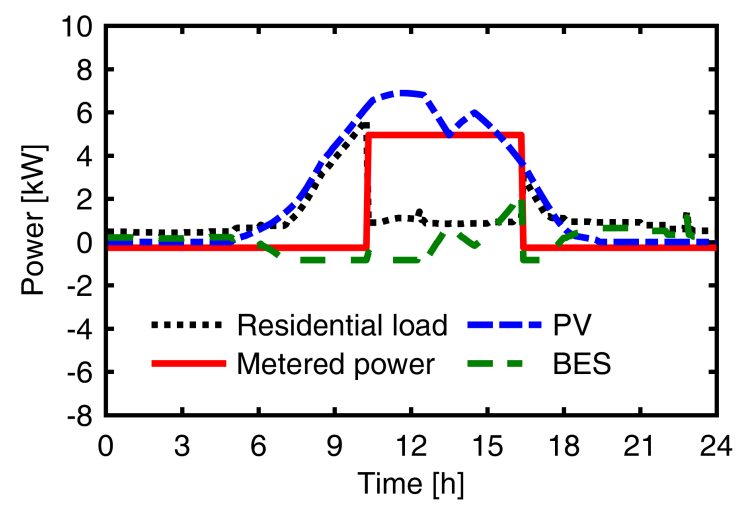

(c)

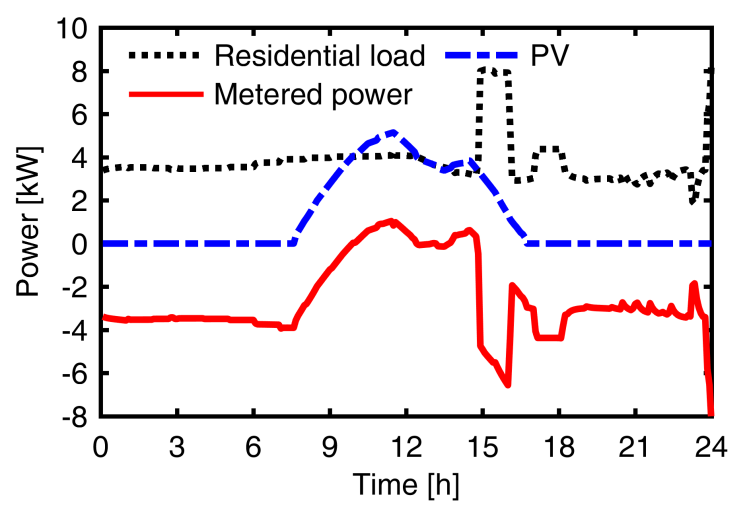

(b)

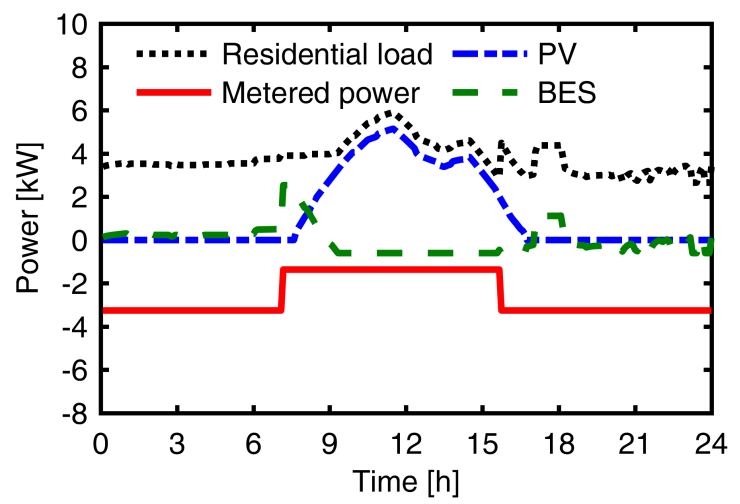

(d)

Figure 5. Impact of weather and virtual power plant coordinated controls of energy storage on the power flow to the district network on two representative days in the Californian mild climate. The loads in the summer are rather lower due to the mild Sacramento, CA, climate. Winter's day with the load dominated by the space heating load. Power flow in a home equipped with a solar panel, but no storage, on (a) a summer's day, and (b) a winter's day. Power flow in a home with solar panels and coordinated control of energy storage systems on the same (c) summer's day and, (d) winter's day. The operation schedules of the hybrid energy storage system allow constant power over a long period of time to the grid, thereby mitigating issues related to the variability of solar energy.

power flow. Likewise, the power fluctuations for a given rating of the BES, are also influenced by the weather, which impacts both the load and generation, for instance larger variations are observed in summer as compared to winter (Figs. 5 (c) and (d)). The ratings of the battery and EWH systems can be found from an optimization study, using weather and load data on design days.

The simulation framework used in this work includes home load models developed using EnergyPlus, and solar PV generation calculated according to the weather data. In this study, each home is considered to have a solar panel rated for $10 \mathrm{~kW}$, and a 50 -gallon water heater rated for $5 \mathrm{~kW}$. The size of inverter and converter is assumed to be large enough in the house. Other relationships are derived from analytical equations, as explained below. The power balance for each home is expressed as

$$
\begin{array}{r}
P_{P V}(t)+P_{B E S}(t)=P_{h}(t)+P_{g}(t), \\
P_{h}(t)=P_{E W H}(t)+P_{h 1}(t)
\end{array}
$$

where, $P_{P V}(t)$ is the PV power generation; $P_{B E S}(t)$, the battery power; $P_{h}$, the total home load; $P_{g}(t)$, the power output to the grid; $P_{E W H}$, the EWH load; and $P_{h 1}(t)$, the home load excluding the EWH.

It may be noted that the energy consumed by the electric water heater depends on the hot water demand, and is therefore the same in both fixed and variable power EWH types.

The simulation step is set to 5 minutes, and $P_{B E S}(t)$, $P_{E W H}(t)$ and $P_{g}(t)$ have 288 elements over a span of 24 hours. Considering each home as a controllable generator, power delivery to the grid is set to a constant value for a duration of time, as defined by

$$
P_{g}= \begin{cases}P_{1} & 0 \leq t \leq t_{1} \\ P_{2} & t_{1} \leq t \leq t_{2} \\ P_{1} & t_{2} \leq t \leq 24\end{cases}
$$

and therefore, only 4-parameters are required to define $P_{g}(t)$, i.e. $P_{1}, P_{2}, t_{1}, t_{2}$

Upon the integration of (1) over the whole day, setting $\int P_{B E S}(t) d t=0$ yields

$$
E_{P V}=E_{h}+\int P_{g}(t) d t
$$




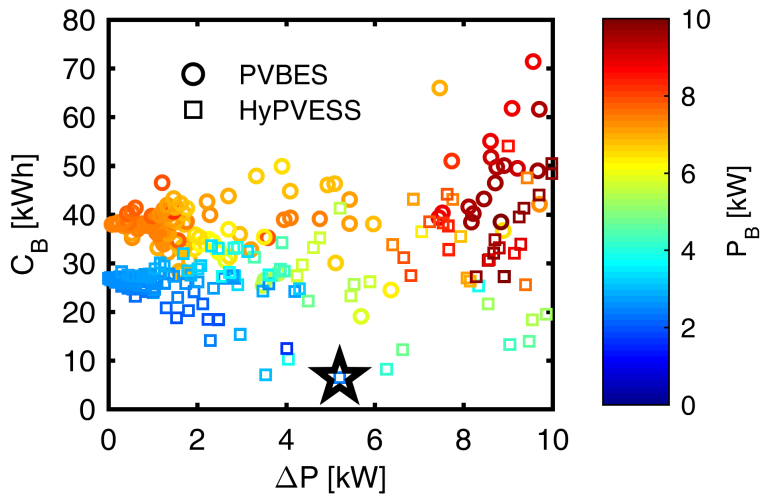

(a)

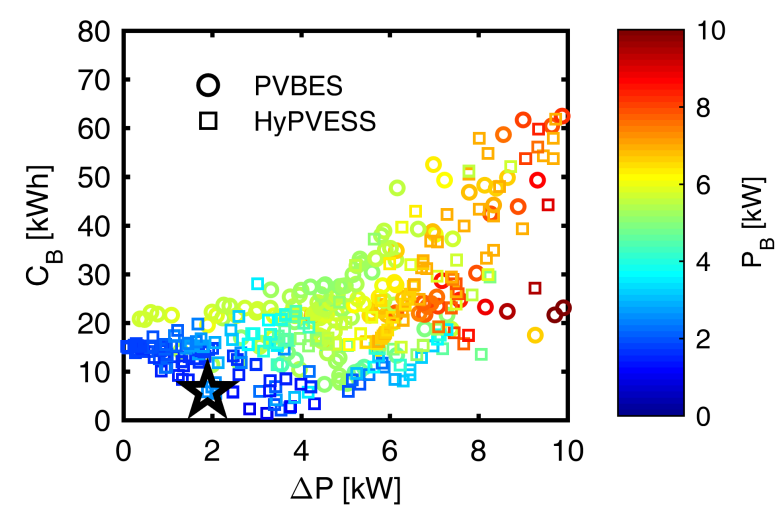

(b)

Figure 6. The variation of battery energy capacity, $C_{B}$ with grid power fluctuation, $\triangle P$ evaluated for several thousand values of $P_{1}, P_{2}$ and $t_{1}$ in NZE homes equipped with only BES and PV (PVBES), and the hybrid PV energy storage system (HyPVESS) on a representative (a) summer's day and (b) winter's day. As expected, the higher $C_{B}$, the smaller $\Delta P$. The use of the hybrid energy storage system leads to a significantly smaller battery energy and power ratings on both types of days considered. A battery rated for $6.5 \mathrm{kWh}$ and $2 \mathrm{~kW}$ is selected and marked with a $\hat{k}$.

where, $E_{P V}$ and $E_{h}$ are energy generation by the solar PV system, and home energy consumption over a day respectively. Both these terms are fixed for given weather and residential load data, and thus, the term $\int P_{g}(t) d t$ can be calculated. This can be used to eliminate one of the 4-parameters composing the grid power definition using

$$
\int P_{g}(t) d t=P_{1} \cdot t_{1}+\left(P_{2}\right) \cdot\left(t_{2}-t_{1}\right)+P_{1} \cdot\left(24-t_{2}\right)
$$

A multi-objective optimization problem using $P_{1}, P_{2}$ and $t_{1}$ as variables is set up. The objectives considered are variation in grid output power, maximum battery power, and battery energy capacity. The variation in grid power flow is defined as

$$
\Delta P=\left|P_{1}-P_{2}\right|
$$

At each instant of time, for a specified value of $P_{g}$, and knowing the values of $P_{P V}$ and $P_{h 1}$, the term $P_{B E S}-P_{E W H}$ can be calculated using (1). The battery and water heater schedules are separated based on considering that the water heater is capable of only energy absorption, unlike the battery

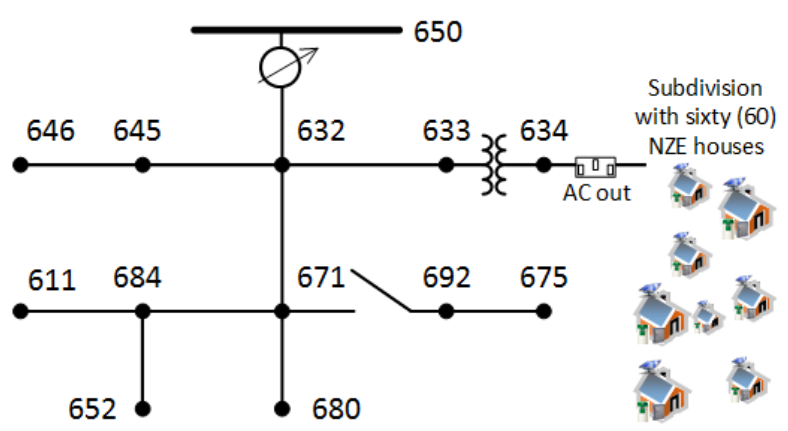

Figure 7. The IEEE 3-phase single line diagram 13-node feeder test case is adopted for the district level simulation. Sixty NZE houses, with PV panels of $10 \mathrm{~kW}$, battery ratings ranging from $5 \mathrm{kWh}$, rated for a maximum instantaneous load of $10 \mathrm{~kW}$, at a power factor of 0.95 are linked to node 634 .

which can sink or source power. Furthermore, the EWH schedule is co-ordinated with the PV power generation such that as far as possible it operates when solar energy is in abundance.

Several thousand candidate values of these optimization variables are considered, and the process is exemplified for home load and PV generation on a summer's and winter's day in California (Fig. 6). It is seen that a $6.5 \mathrm{kWh}$ battery, rated for $2.5 \mathrm{~kW}$ would achieve power delivery to the grid with a maximum fluctuation of $5 \mathrm{~kW}$ in summer, and only $2 \mathrm{~kW}$ in winter. It is worth noting that this battery rating is approximately half that marketed by commercial battery manufacturers [8].

\section{InTERCONNECTION With IEEE-13 Node Test FEEDER SYSTEM}

The behavior of the NZE homes at the district level is modeled by interconnection with an IEEE-13 node test feeder system, which is described in [9]. Sixty NZE homes with residential load and PV generation profiles modified according to the number of occupants and local weather variations are connected to node 634 (Fig. 7). The power factor is set to 0.95 for each house.

Three types of homes, traditional i.e. without solar PV and BES; PVStd, including EWH with conventional controls and no batteries (Fig. 2 (a)), and the proposed HyPVESS containing both solar panels, batteries, and EWH with controls coordinated with solar PV generation (Fig. 2 (b)) are examined to verify the benefits of the proposed HyPVESS at the district level. OpenDSS is used for simulation studies, and load and generation profiles for the homes on two representative days, one in the Californian winter and the other in the summer are considered. In case of the HyPVESS homes, the battery and EWH schedules and ratings are derived for each home as detailed in Section III. Power flow at the node 634 is monitored.

Homes of the PVStd type, which contain no storage can achieve NZE targets by feeding power to the utility during periods of plentiful solar power, and absorbing it when solar 
generation reduces. One of the limitations associated with this type of operation is that PV generation and load demand peaks are not coincident, leading to an excess inflow of power into the utility at and around midday. In contrast, during the evening, PV generation diminishes, and load demands rise, therefore excess power is absorbed from the utility grid at this time. This type of behavior leads to a large rate of change of load, which would be exacerbated for high PV penetration communities (Figs. 8 (a) and (b)). For large PV communities, a power system incorporating a number of fast responding gas plants would be required to service this rate of change of load, requiring tremendous investment. Moreover, the peaks of power inflow and outflow could potentially cause issues including overloading of distribution lines, transformers, and excessive voltage drop.

In contrast, when the homes are equipped with the HyPVESS, each one behaves like a flexible and controllable generator (Figs. 8 (a) and (b)). It is observed that the peaks of power flow to the grid are reduced to more than half as compared with the PVStd case in both summer and winter (Figs. 8 (a) and (b). In addition, the rate of change of load is significantly smaller with the HyPVESS.

\section{CONCLUSION}

This paper proposed a hybrid PV energy storage system (HyPVESS) for energy storage in net zero energy (NZE) homes. The newly introduced system includes a battery and a variable power electric water heater $(\mathrm{EWH})$ with weather and virtual power plant (VPP) coordinated controls. The benefits of the proposed hybrid system stem from the fact that the BES and EWH operation can be scheduled such that the NZE home supplies dispatchable power or behaves like a controllable load.

A methodology for sizing and scheduling the BES operation was outlined. It was demonstrated through multi-objective differential evolution that the use of variable power EWH with solar PV coordinated controls, in conjunction with a BES to supply a specified power to the utility, leads to significant reductions in battery capacity.

Furthermore, benefits at the district level were verified through simulations of NZE homes interconnected to an IEEE13 node test feeder system. It was shown that the proposed HyPVESS can mitigate the problem of high load variation presented to the utility by communities with high PV penetration. While traditional systems curtail PV generation to address this challenge, the hybrid system can operate the solar PV system at the maximum power point at all times, which results in significant cost and energy savings. The proposed technology has the potential to mitigate the challenges stemming from solar power variability.

\section{ACKNOWLEDGMENT}

The support of University of Kentucky, the L. Stanley Pigman endowment and the SPARK program is gratefully acknowledged.

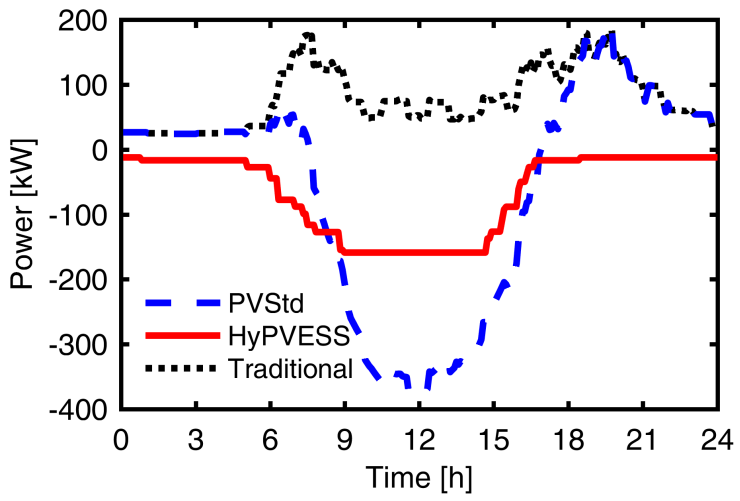

(a)

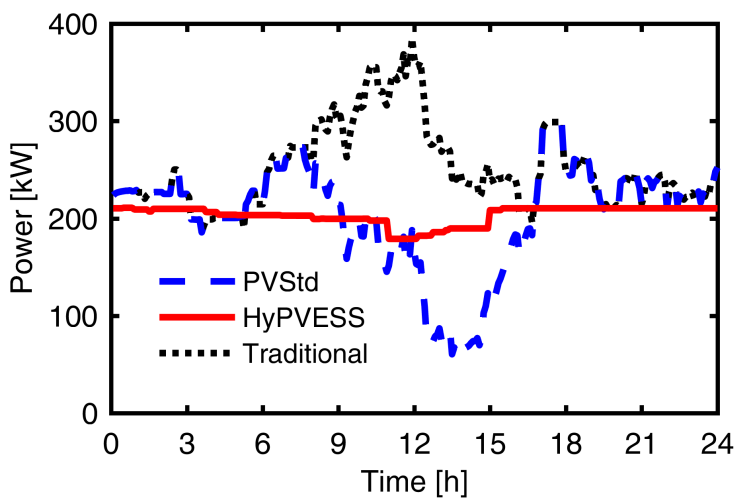

(b)

Figure 8. Power flow profile at node 634 of the IEEE 13-bus test system from Fig. 7 on (a) a summer day and (b) a winter day. Note that homes behave as generators in summer and loads in winter. The hybrid PV energy storage system, HyPVESS, with virtual power plant (VPP) controls, ensures constant power flow for specified time duration in summer, thereby mitigating the 'duck curve' profile observed in the case of homes without storage.

\section{REFERENCES}

[1] "California Public Utilities Commission," http://www.cpuc.ca.gov/ZNE/, accessed: 2018-06-28.

[2] S. Walker, T. Labeodan, W. Maassen, and W. Zeiler, "A review study of the current research on energy hub for energy positive neighborhoods," Energy Procedia, vol. 122, pp. 727-732, 2017.

[3] G. Mavromatidis, K. Orehounig, and J. Carmeliet, "Evaluation of photovoltaic integration potential in a village," Solar Energy, vol. 121, pp. 152-168, 2015.

[4] A. Sangwongwanich, Y. Yang, and F. Blaabjerg, "High-performance constant power generation in grid-connected pv systems," IEEE Transactions on Power Electronics, vol. 31, no. 3, pp. 1822-1825, 2016.

[5] M. Zeraati, M. E. H. Golshan, and J. Guerrero, "Distributed control of battery energy storage systems for voltage regulation in distribution networks with high pv penetration," IEEE Transactions on Smart Grid, 2016.

[6] J. Dickert and P. Schegner, "A time series probabilistic synthetic load curve model for residential customers," in PowerTech, 2011 IEEE Trondheim. IEEE, 2011, pp. 1-6.

[7] Z. Zhao, W. C. Lee, Y. Shin, and K.-B. Song, "An optimal power scheduling method for demand response in home energy management system," IEEE Transactions on Smart Grid, vol. 4, no. 3, pp. 1391-1400, 2013.

[8] “Tesla Powerwall," https://www.tesla.com/powerwall, accessed: 2018-0628.

[9] W. H. Kersting, "Radial distribution test feeders," in 2001 IEEE Power Engineering Society Winter Meeting. Conference Proceedings (Cat. No.01CH37194), vol. 2, 2001, pp. 908-912 vol.2. 